Journal of Applied Pharmaceutical Science Vol. 6 (05), pp. 131-136, May, 2016

Available online at http://www.japsonline.com

DOI: $10.7324 / \mathrm{JAPS} .2016 .60520$

ISSN 2231-3354 (cc) BY-NC-SA

\title{
Antifungal activity of essential oil from the fruits of Ammodaucus leucotrichus Coss. \& Dur., in liquid and vapour phase against postharvest phytopathogenic fungi in apples
}

\author{
M. Manssouri ${ }^{1}$, M. Znini ${ }^{1}$, A. El Harrak ${ }^{2}$, L. Majidi ${ }^{1 *}$ \\ ${ }^{1}$ Université My Ismail, Laboratoire des Substances Naturelles \& Synthèse et Dynamique Moléculaire, Faculté des Sciences et Techniques, BP 509, 52003, \\ Errachidia, Morocco., ${ }^{2}$ Université My Ismail, Laboratoire de Protection \& Amélioration et Ecophysiologie Végétale, Faculté des Sciences et Techniques, \\ BP 509, Errachidia, Morocco.
}

\begin{tabular}{|c|c|}
\hline ARTICLE INFO & ABSTRACT \\
\hline Article history: & \multirow{8}{*}{$\begin{array}{l}\text { The aim of this study was to evaluate the antifungal activity of essential oil (EO) from Ammodaucus } \\
\text { leucotrichus fruits against three phytopathogenic fungi causing the deterioration for apples, including Botrytis } \\
\text { cinerea, Penicillium expansum and Rhizopus stolonifer by using the poisoned food (PF) and the volatile activity } \\
\text { (VA) methods. The antifungal test results indicated that the EO displayed significant potential of antifungal } \\
\text { activity against the tested phytopathogenic fungi }(p<0.05 \text { ). In PF technique, the MICs (minimums inhibitory } \\
\text { concentrations) were } 0.5 \mu \mathrm{L} / \mathrm{mL} \text { for } B \text {. cinerea and } P \text {. expansum and } 1 \mu \mathrm{L} / \mathrm{mL} \text { for } R \text {. stolonifer. Whereas, in VA } \\
\text { assay, the complete inhibition of the mycelial growth of } B \text {. cinerea and } P \text {. expansum was observed at MIC= } \\
0.125 \mu \mathrm{L} / \mathrm{mL} \text { air, and that of } R \text {. stolonifer was observed at } \mathrm{MIC}=0.25 \mu \mathrm{L} / \mathrm{mL} \text { air. The overall results suggest } \\
\text { that } A \text {. leucotrichus essential oil have a potential as antifungal preservatives for the control of postharvest } \\
\text { diseases of apple. }\end{array}$} \\
\hline Received on: $23 / 12 / 2015$ & \\
\hline Revised on: $25 / 01 / 2016$ & \\
\hline Accepted on: 10/02/2016 & \\
\hline Available online: $28 / 05 / 2016$ & \\
\hline Key words: & \\
\hline Ammodaucus leucotrichus, & \\
\hline $\begin{array}{l}\text { Essential oil, Antifungal } \\
\text { activity, Phytopathogenic } \\
\text { fungi, Apple. }\end{array}$ & \\
\hline
\end{tabular}

\section{INTRODUCTION}

Apple constitutes the most important human food, serving as the primary source of calories for the majority of the world's population. To provide fruit throughout the year, fresh apples are stored after harvest. However, postharvest losses caused by fungal diseases are the major factor limiting the storage life of apples. Indeed, many pathogens including Botrytis cinerea (gray mold), Penicillium expansum (blue mold), and Rhizopus stolonifer (Rhizopus soft rot) reduce the market values and deteriorate the quality of fruits and render (Znini et al., 2011).Traditionally, chemical treatments, by the application of synthetic fungicides, are considered to be the most effective and cheapest method of controlling postharvest diseases (Eckert and Ogawa, 1988). However, the emergence of strains of pathogens resistant to these fungicides, as well as the growing concern for

* Corresponding Author

Email:Imajidi@yahoo.fr

Tel : (+212)535574497., Fax : (+212)535574485 human safety and the potential impact on environment largely limits their application and compels us to look for alternatives to the use of synthetic fungicides to control postharvest diseases (Suhr and Nielsen, 2003). Recently, interests have been generated in the development of safer anti-fungal agents such as plant-based essential oil sand extracts to control phytopathogens in food and agriculture industries (Gumus et al., 2010). Essential oils are made up of many different volatile compounds and their production by plants is believed to be predominantly a defense mechanism against pathogens and pests, and they have been shown to possess antimicrobial and antifungal properties (Znini et al., 2011). They are considered as non-phytotoxic compounds, less environmental effects, and wide public acceptance (Znini et al., 2011; Gumus et al., 2010). Ammodaucus leucotrichus is the only one specie of the genus Ammodaucus in the Apiaceae family (Ozenda, 1991). It inhabits the maritime sands in the Saharan and sub-Saharan countries of North Africa, Morocco, Algeria and Tunisia, extending to Egypt and tropical Africa (Maberly, 1998). 
In Morocco, which locally known as "kammûnes-sofi or ikâman", the fruits are used either by the local population as a powder or in a decoction to treat gastric-intestinal pain, gastralgias and indigestion (Bellakhdar, 1979). It is also frequently used, as an infusion, for diverse infantile diseases of the digestive apparatus: dysentery, nausea, regurgitation, vomiting. Previous studies reported that the essential oils of A. leucotrichus exhibited the antimicrobial activities against bacteria, yeasts and filamentous fungi (Abu Zarga et al., 2013; El-Haci et al., 2014). It was also reported that aqueous extracts of A. leucotrichus were shown to inhibit the formation of calcium oxalate monohydrate crystals and also found to potently inhibit the nucleation, growth and aggregation phases of calcium oxalate crystallization (Beghali et al., 2008). Recently, we have reported the first studied of the chemical composition of essential oil of A. leucotrichus and its application as a green inhibitor for the corrosion of steel in $1 \mathrm{M}$ $\mathrm{HCl}$ (Manssouri et al., 2015). As far as our literature survey could ascertain, antifungal activities of A. leucotrichu against phytopathogens causing severe diseases in apples have not previously been published. Therefore, the aim of this paper was to evaluate the antifungal properties of A. leucotrichus essential oil against three phytopathogens, such as Botrytis cinerea, Penicillium expansum, and Rhizopus stolonifer by using the poisoned food (PF) and the volatile activity (VA) methods.

\section{MATERIAL AND METHODS}

\section{Plant material}

The fruits of A. leucotrichus were harvested in March 2012 (full bloom) from Alnif-Errachidia (Morocco). Voucher specimens were deposited in the herbarium of the Faculty of Sciences and Technology of Errachidia (Morocco).

Table 1: Chemical composition of A. leucotrichus fruits essential oil from

\begin{tabular}{|c|c|c|c|c|c|}
\hline $\mathbf{N}^{\mathbf{a}}$ & Components & $\mathbf{R I} l^{\mathrm{b}}$ & $\mathbf{R I} a^{\mathbf{c}}$ & RI $p^{\mathrm{d}}$ & $\%^{\mathrm{e}}$ \\
\hline 1 & $\alpha$-Pinene & 936 & 928 & 1021 & 1.1 \\
\hline 2 & $\beta$-Pinene & 978 & 966 & 1109 & 0.5 \\
\hline 3 & Myrcene & 987 & 976 & 1158 & 0.2 \\
\hline 4 & 3-Carene & 1010 & 1001 & 1147 & 0.7 \\
\hline 5 & Limonene & 1025 & 1019 & 1204 & 12.5 \\
\hline 6 & Cuminaldehyde & & 1210 & 1781 & 1.6 \\
\hline 7 & Perillaldehyde & 1260 & 1251 & 1772 & 73.5 \\
\hline 8 & $\alpha$-Terpinen-7-al & & 1267 & 1772 & 1.3 \\
\hline 9 & $\gamma$-Terpinen-7-al & & 1279 & 1854 & 1.5 \\
\hline 10 & Methyl perillate & 1381 & 1372 & 1985 & 1.8 \\
\hline \multicolumn{5}{|c|}{ Total identified } & 94.7 \\
\hline \multicolumn{5}{|c|}{ Monoterpene hydrocarbons } & 15.0 \\
\hline \multicolumn{5}{|c|}{ Oxygenated monoterpenes } & 79.7 \\
\hline
\end{tabular}

${ }^{\mathrm{a}}$ Order of elution are given on apolar column (Rtx-1);

${ }^{b} \mathbf{R I} \boldsymbol{l}=$ retention indices on the apolar column (Rtx-1) in literature;

${ }^{c} \mathbf{R I} \boldsymbol{a}=$ retention indices on the apolar column ( Rtx-1) ;

${ }^{\mathrm{d}} \mathbf{R I} \boldsymbol{p}=$ retention indices on the polar column (Rtx-Wax);

${ }^{e}$ Relative percentages of components $(\%)$ are calculated on GC peak areas on the apolar column (Rtx-1).

\section{Essential oil isolation}

The EO was prepared by hydrodistillation for $3 \mathrm{~h}$ using a Clevenger type apparatus and analyzed by gas chromatography (GC) and gas chromatography/mass spectroscopy (GC/MS). A total of 10 components, accounting for $94.7 \%$ of the total oil, were identified (Table 1). It contained peryllaldehyde $7(73.5 \%)$ followed by limonene $5(12.5 \%)$ were the major components (Manssouri et al., 2015).

\section{Fungal species and in vitro antifungal activity}

Three fungal isolates causing apples rot: $B$. cinerea, $P$. expansum and $R$. stolonifer were isolated directly from rooted apples collected from different rooms in Midelt station (Morocco). All isolated fungal species were transferred to sterilized three replicates $9 \mathrm{~cm}$ Petri dishes containing fresh Potato Dextrose agar (PDA) medium in the presence of a quantity of streptomycin (50 $\mathrm{mg} / \mathrm{L})$ to stop the growth of bacteria. The plates were incubated at $25 \pm 2{ }^{\circ} \mathrm{C}$ for 7 days and darkness. The developing fungal colonies were purified and identified up to the species level by microscopic examination through the help of the following references (Barnett and Hunter, 1972).

The antifungal activity of the essential oil of $A$. leucotrichus fruit against fungi isolated was undertaken using the poisoned food (PF) method (Rhayour at al., 2003) and the volatile activity (VA) assay (Soylu et al., 2010). In PF, the essential oil were dispersed as an emulsion in sterile agar suspension $(0.2 \%)$ and added to PDA immediately before it was emptied into the glass Petri dishes $(90 \times 20 \mathrm{~mm}$ in diameter $)$ at a temperature of 40 $45^{\circ} \mathrm{C}$. The concentrations tested were: $0.125,0.25,0.5,1$ and 2 $\mu \mathrm{L} / \mathrm{mLPDA}$. The control received the same quantity of sterile agar suspension $(0.2 \%)$ mixed with PDA. The tested fungi were inoculated with $6 \mathrm{~mm}$ mycelial plugs from 7-days-old cultures cut with a sterile cork and incubated for 11 day for $B$. cinerea, 7 days for $P$. expansum and 30 hours for $R$. stolonifer at $25 \pm 2{ }^{\circ} \mathrm{C}$.

In VA assay, the Petri dishes $(90 \times 20 \mathrm{~mm})$ were filled with $20 \mathrm{~mL}$ of potato dextrose agar (PDA) medium and then seeded with a mycelial disc (6 $\mathrm{mm}$ diameter), cut from the periphery of 7-days--old mycelium culture of the tested fungi. The Petri dishes $(90 \times 20 \mathrm{~mm}$, which offer $80 \mathrm{~mL}$ air spaces after addition of $20 \mathrm{~mL}$ agar media) were inverted and sterile filter paper discs (9 $\mathrm{mm}$ in diameter) impregnated with different concentrations of essential oil $(0.125,0.25,0.5,1$ and $2 \mu \mathrm{L} / \mathrm{mL}$ air) are deposited on the inverted lid and incubated for 11 day for B. cinerea, 7 days for $P$. expansum and 30 hours for $R$. stolonifer at $25 \pm 2{ }^{\circ} \mathrm{C}$. For corresponding control equal amount of water was poured on the sterilized paper filter.

In both types of experiments, three replicate plates were inoculated for each treatment (fungi/amount) and the experiment was conducted three times and the mycelial growth was followed by measuring the diameter following two perpendicular lines passing by the centre of the dish. Fungi-toxicity of essential oil was expressed in terms of percentage of mycelial growth inhibition (I \%) and calculated following the formula (Pandey et al., 1982).

$$
I(\%)=\frac{D_{t}-D_{i}}{D_{t}} \times 100
$$

with $\mathrm{D}_{\mathrm{t}}=$ Average diameter of fungal colony in control. $\mathrm{D}_{\mathrm{i}}=$ Average diameter of fungal colony in treatment. The lowest 
concentration that completely inhibited the growth of the fungus was considered the minimum inhibitory concentration (MIC).

\section{Transfer experiments}

The fungistatic-fungicidal nature of essential oil was tested by observing revival of growth of the inhibited mycelial disc following its transfer to non-treated PDA. A fungicidal effect was where there was no growth, whereas a fungistatic effect was where temporary inhibition of microbial growth occurred.

\section{Data analysis}

The inhibitory effect of essential oil on mycelia growth was analyzed by an analysis of variance (ANOVA). Mean and standard error of data were calculated using SPSS program version 15.0 for Windows. The separation of means was done by using the least significant difference (LSD) test at $p<0.05$.

\section{RESULTS AND DISCUSSION}

\section{Results}

The antifungal activity obtained by PF and VA techniques with different concentrations of essential oil of $A$. leucotrichus was reported in Tables 2 and 3, respectively. In both techniques, the results indicate that the inhibition of the mycelial growth of each train was significantly influenced by the essential oil concentration $(p<0.05)$. Also, the percentage inhibition of mycelia growth increased with increasing amounts of essential oil for all the strains tested suggesting that this oil inhibited the growth of all the strains in a dose-dependent manner.

Table 2: Antifungal activity of $A$. leucotrichus essential oil against $B$.cinerea, $P$. expansum and $R$. stolonifer at various concentrations using PF technique.

\begin{tabular}{|c|c|c|c|}
\hline Strain & B. cinerea & P. expansum & R. stolonifer \\
\hline Incubation time & $\begin{array}{c}11 \text { days } \\
25 \pm 2{ }^{\circ} \mathrm{C}\end{array}$ & $\begin{array}{c}7 \text { days } \\
25 \pm 2^{\circ} \mathrm{C}\end{array}$ & $\begin{array}{c}60 \text { hours } \\
25 \pm 2^{\circ} \mathrm{C}\end{array}$ \\
\hline \multicolumn{4}{|c|}{ Concentration $(\mu \mathrm{L} / \mathrm{mL})$} \\
\hline 2 & $100 \pm 0.00^{\text {a. } 1}$ & $100 \pm 0.00^{\text {a. } 1}$ & $100 \pm 0.00^{\text {a. } 1}$ \\
\hline 1 & $100 \pm 0.00^{\text {a. } 1}$ & $100 \pm 0.00^{\text {a. } 1}$ & $100 \pm 0.00^{\text {a. } 1}$ \\
\hline 0.5 & $100 \pm 0.00^{\text {a. } 1}$ & $100 \pm 0.00^{\text {a. } 1}$ & $75.00 \pm 0.00^{\text {b. } 2}$ \\
\hline 0.25 & $82.22 \pm 0.57^{\text {b. } 1}$ & $73.33 \pm 1.85^{\text {b. } 2}$ & $69.44 \pm 2.83^{\text {c. } 3}$ \\
\hline 0.125 & $65.23 \pm 4.83^{\text {c. } 1}$ & $55.22 \pm 1.83^{\text {c. } 2}$ & $33.23 \pm 2.32^{\text {d. } 3}$ \\
\hline
\end{tabular}

Mean values ( \pm standard deviation) followed by different (column) and numbers (line) in each row indicate significant differences $(p<0.05)$ by least significant difference test (LSD).

Using the PF technique, the results (Table 2 and Fig. 1) indicate that the $B$. cenerea, and $P$. expansum showed a strong sensitivity to $A$. leucotrichus essential oil at all concentrations. The inhibition rate reached $65.23 \%$ for $B$. cinerea, and $55.22 \%$ for $P$. expansum at $0.125 \mu \mathrm{L} / \mathrm{mL}$, and complete inhibition effect $(100 \%)$ was observed at $0.5 \mu \mathrm{L} / \mathrm{mL}$, indicating that this latter concentration was the MIC of A. leucotrichus oil against two strains tested. Whereas it displayed moderate-high antifungal activity against $R$. stolonifer, the percentage inhibition increases moderately with the concentration reaching the complete inhibition $(100 \%)$ to $1 \mu \mathrm{L} / \mathrm{mL}$, indicating that MIC was $1 \mu \mathrm{L} / \mathrm{mL}$ against $R$. stolonifer. Moreover, it is important to know the fungitoxic nature of the essential oil against $B$. cinerea and $P$. expansum at 0.5 to $2 \mu \mathrm{L} / \mathrm{mL}$ and at 1 to $2 \mu \mathrm{L} / \mathrm{mL}$ for $R$. stolonifer. Indeed, the transfer of mycelial discs where growth inhibition was complete by essential oil into PDA medium without this oil, showed that mycelial growth of R. stolonifer grew after incubation for first hour, indicating a fungistatic effect of this oil against this strain (MFC >2 $\mu \mathrm{L} / \mathrm{mL}$ ). Whereas no mycelial growth was observed in $B$. cinerea and $P$. expansum after treatment with oil at 0.5 to $2 \mu \mathrm{L} / \mathrm{mL}$, indicating a fungicidal effect of this oil against these strains $(\mathrm{MFC}=0.5 \mu \mathrm{L} / \mathrm{mL})$. Therefore, the plant phytopathogens studied can be classified according to their sensitivity to the oil in the following order: $B$. cinerea $>P$. expansum $>$ R. stolonifer.

Using VA assay, the results (Tables 3 and Fig. 2) showed that the activity of the vapour of the A. leucotrichus essential oil was more pronounced for all strains tested. This volatile fraction completely suppressed the growth $(100 \%)$ of $B$. cinerea and $P$. expansum at $0.125 \mu \mathrm{L} / \mathrm{mL}$ air, indicating that the MIC for both strains was $0.125 \mu \mathrm{L} / \mathrm{mL}$ air, whereas, the mycelial growth of $R$. stolonifer was totally inhibited at $0.25 \mu \mathrm{L} / \mathrm{mL}$ air (MIC value).

Table 3: Antifungal activity of A. leucotrichus essential oil vapour against $B$. cinerea, $P$. expansum and $R$. stolonifer at various concentrations using VA assay

\begin{tabular}{cccc}
\hline Strain & $\boldsymbol{B}$. cinerea & P. expansum & $\boldsymbol{R}$. stolonifer \\
\hline Incubation time & $\begin{array}{c}\mathbf{1 1} \text { days } \\
\mathbf{2 5} \pm \mathbf{2}^{\circ} \mathbf{C}\end{array}$ & $\begin{array}{c}\mathbf{7} \text { days } \\
\mathbf{2 5} \pm \mathbf{2}^{\circ} \mathbf{C}\end{array}$ & $\begin{array}{c}\mathbf{6 0} \text { hours } \\
\mathbf{2 5} \pm \mathbf{2}^{\circ} \mathbf{C}\end{array}$ \\
\hline \multicolumn{2}{c}{ Concentration $(\boldsymbol{\mu L} / \mathbf{m L}$ air) } & & \\
2 & $100 \pm 0.00^{\text {a. } 1}$ & $100 \pm 0.00^{\text {a. } 1}$ & $100 \pm 0.00^{\text {a. } 1}$ \\
1 & $100 \pm 0.00^{\text {a. } 1}$ & $100 \pm 0.00^{\text {a. } 1}$ & $100 \pm 0.00^{\text {a. } 1}$ \\
0.5 & $100 \pm 0.00^{\text {a. } 1}$ & $100 \pm 0.00^{\text {a. } 1}$ & $100 \pm 0.00^{\text {a. } 1}$ \\
0.25 & $100 \pm 0.00^{\text {a. } 1}$ & $100 \pm 0.00^{\text {a. } 1}$ & $100 \pm 0.00^{\text {a. } 1}$ \\
0.125 & $100 \pm 0.00^{\text {a. } 1}$ & $100 \pm 0.00^{\text {a. } 1}$ & $82.36 \pm 0.33^{\text {b. 2 }}$ \\
\hline
\end{tabular}

Mean values ( \pm standard deviation) followed by different (column) and numbers (line) in each row indicate significant differences $(p<0.05)$ by least significant difference test (LSD).

Moreover, after growth inhibition had been established with A. leucotrichus essential oil vapour, it is important to know the fungitoxic nature of the fraction volatile of this oil. Indeed, the mycelial discs, which $100 \%$ inhibition, were transferred onto PDA medium without this oil and the results showed that no mycelial growth was observed for $B$. cinerea after treatment with oil at all concentration. Also, the fungal growth of $P$. expansum was observed only after treatment with $0.125 \mu \mathrm{L} / \mathrm{mL}$ air. However, fungal growth of $R$. stolonifer was observed after treatment only with $0.25 \mu \mathrm{L} / \mathrm{mL}$ air. Thus, A. leucotrichus essential oil vapour showed fungicidal activity against $B$. cinerea at $\mathrm{MFC}=0.125$ $\mu \mathrm{L} / \mathrm{mL}$ air, while against $P$. expansum, the oil exhibited fungicidal activity at $\mathrm{MFC}=0.25 \mu \mathrm{L} / \mathrm{mL}$ air and fungistatic activity at $\mathrm{MIC}=$ $0.125 \mu \mathrm{L} / \mathrm{mL}$ air. For $R$. stolonifer, the fraction volatile of oil exhibited fungicidal activity at $\mathrm{MFC}=0.5 \mu \mathrm{L} / \mathrm{mL}$ air and fungistatic activity at $\mathrm{MIC}=0.25 \mu \mathrm{L} / \mathrm{mL}$ air. Therefore, the plant phytopathogens studied can be classified according to their sensitivity to the A. leucotrichus essential oil in the following order: B. cinerea $>$ P. expansum $>$ R. stolonifer. 
B. cinerea

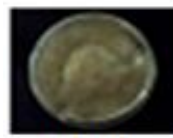

$0 \mu \mathrm{L} / \mathrm{mL}$

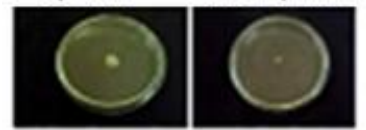

$0.25 \mu \mathrm{L} / \mathrm{mL}$

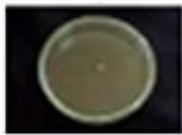

$1 \mu \mathrm{L} / \mathrm{mL}$
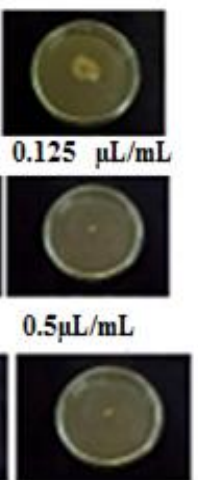

$2 \mu \mathrm{L} / \mathrm{mL}$
P. expansum

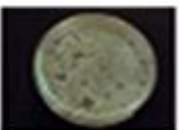

$0 \mu \mathrm{L} / \mathrm{mL}$

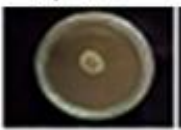

$0.25 \mu \mathrm{L} / \mathrm{mL}$

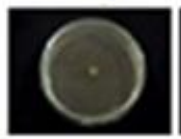

$1 \mu \mathrm{L} / \mathrm{mL}$

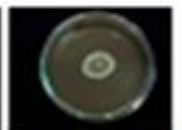

$0.125 \mu \mathrm{L} / \mathrm{mL}$

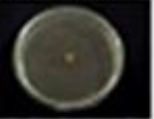

$0.5 \mu \mathrm{L} / \mathrm{mL}$

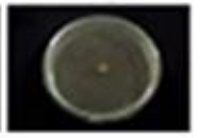

$2 \mu \mathrm{L} / \mathrm{mL}$

\section{R. stolonifer}

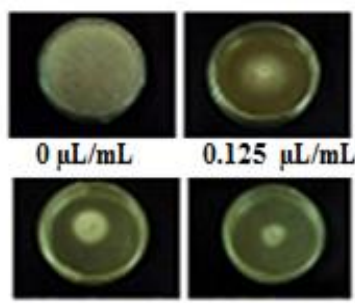

$0.25 \mu \mathrm{L} / \mathrm{mL} \quad 0.5 \mu \mathrm{L} / \mathrm{mL}$

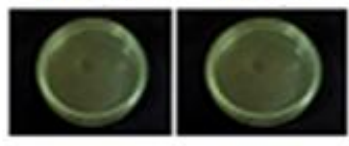

$1 \mu \mathrm{L} / \mathrm{mL} \quad 2 \mu \mathrm{L} / \mathrm{mL}$

Fig. 1: Effect of various concentrations of the essential oil of A. leucotrichus on mycelial growth of three isolated fungal strains.

B. cinerea

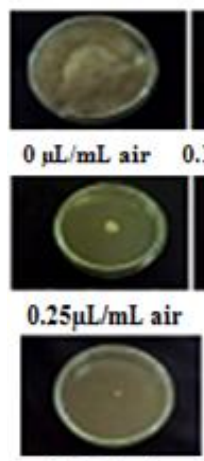

$1 \mu \mathrm{L} / \mathrm{mL}$ air

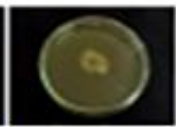

$0.125 \mu \mathrm{L} / \mathrm{mL}$ air

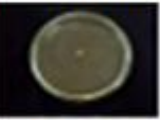

$0.5 \mu \mathrm{L} / \mathrm{mL}$ air

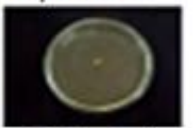

$2 \mu \mathrm{L} / \mathrm{mL}$ air
P. expansum

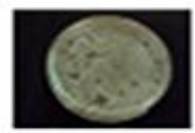

$0 \mu \mathrm{L} / \mathrm{mL}$ air

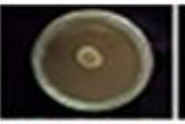

$0.25 \mu \mathrm{L} / \mathrm{mL}$ air $0.5 \mu \mathrm{L} / \mathrm{mL}$ air

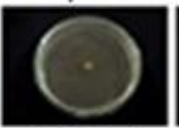

$1 \mu \mathrm{L} / \mathrm{mL}$ air

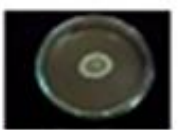

$0.125 \mu \mathrm{L} / \mathrm{mL}$ air
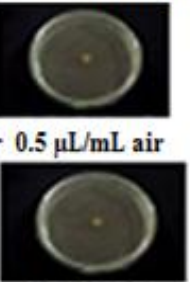

$2 \mu \mathrm{L} / \mathrm{mL}$ air

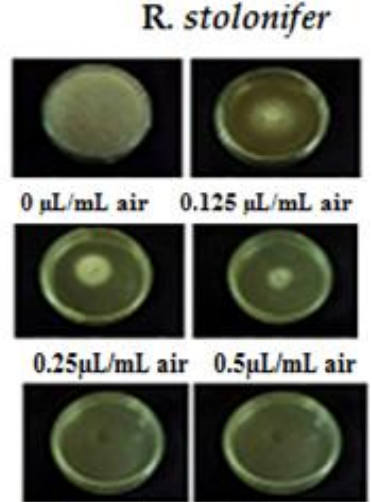

$1 \mu \mathrm{L} / \mathrm{mL}$ air $\quad 2 \mu \mathrm{L} / \mathrm{mL}$ air

Fig. 2: Effect the essential oil vapour of A. leucotrichus at various concentrations on mycelial growth of three isolated fungal.

\section{DISCUSSION}

In the present study, A. leucotrichus essential oil showed antifungal activity against the mycelial growth of all the phytopathogenic fungi studied. The MICs were $0.5 \mu \mathrm{L} / \mathrm{mL}$ and $0.125 \mu \mathrm{L} / \mathrm{mL}$ air for $B$. cinerea and $P$. expansum using PF and VA techniques, respectively. Whereas, for $R$. stolonifer, the MICs were $1 \mu \mathrm{L} / \mathrm{mL}$ and $0.25 \mu \mathrm{L} / \mathrm{mL}$ air using PF and VA techniques, respectively. These results were in accord with those previously reported by et El-Haci et al. which the essential oil of $A$. leucotrichus possessed the most potent activity against filamentous fungi, with MIC values $0.25-0.50 \mu \mathrm{L} / \mathrm{mL}$ for the mycelium growth of Fusarium oxysporum and Aspergillus flavus (El-Haci et al., 2014).

The activity of A. leucotrichus essential oil is probably related to its high levels of oxygenated monoterpenes $(79,7 \%)$, especially its major constituent perillaldehyde (73.5\%). Indeed, Zambonelli et al., (1996) previously concluded that the high activity of oxygenated monoterpenes directed against pathogens results from their interference with enzymatic reactions during cell-wall synthesis, causing changes in cell permeability by disrupting lipid packing and changes to membrane properties and functions. Also, it is reported that perillaldehyde-rich oils are used as food additives for flavor and in perfumery to add spiciness (ElHaci et al., 2014) and perillaldehyde has a sweet mint like odor and originates from essential oils which have been labeled "generally recognized as safe" by the United States Food and Drug Administration (Tolouee et al., 2010). Furthermore, it is, also, reported that perillaldehyde exhibits antifungal activities against and air borne microbes and spoiling-fungi infection of fruits. Indeed, it may be used as an alternative substance to control spoiling-fungi infection in vitro and in vivo of cherry tomatoes (Solanum lycopersicum L.). The mycelial growth of the tested fungi was totally inhibited at 0.5 and $0.08 \mathrm{~mL} / \mathrm{L}$ perillaldehyde in the air at contact and vapor conditions, respectively. Thus, perillaldehyde is suitable for development into a natural food preservative (Tian et al., 2015a). Perillaldehyde was also tested for its influence on microbial count in air by vaporizing with an air washer. The highest antibacterial activity was observed when perillaldehyde was sprayed which was reduced the germ count by $53 \%$ (Sato et al., 2006). Perillaldehyde showed also, notable antifungal activity against $A$. niger, a known cause of grape spoilage, with a minimum inhibitory concentration (MIC) and a minimum fungicidal concentration (MFC) of 0.25 and $1 \mu \mathrm{l} / \mathrm{ml}$, respectively. The accumulation of mycelial biomass was also inhibited by perillaldehyde in a dose-dependent manner, 
completely inhibiting mycelial growth at $1 \mu \mathrm{l} / \mathrm{ml}$ (Tian et al., $2015 b)$. These authors reported that the lipophilic nature of perillaldehyde interacts with the cell membrane of A. niger as a first step in its antifungal activity. The electrical conductivity in the cell suspensions increased above that of the control at all times when perillaldehyde was added, indicating that the permeability of the cell membrane was compromised (Tian et al., 2015b). When perillaldehyde accumulates at the cytoplasmic membrane, changes in the membrane integrity occur, such as expansion (swelling) of the membrane, which may result in a destabilization of the membrane and subsequent ion leakage (Ultee et al., 2002). Another assumption is that perillaldehyde probably acted as a signal that triggered the transcription processes of some specific "fungicidal" genes in the fruits (Panahirad et al., 2012). Further experiments indicated that perillaldehyde activated a membraneactive mechanism that inhibits ergosterol synthesis, increases membrane permeability (as evidenced by extracellular $\mathrm{pH}$ and conductivity measurements), and disrupts membrane integrity, leading to cell death (Tian et al., 2015a). In addition, the components in lower amount may also contribute to antifungal activity of essential involving probably some type of synergism with the other active compounds.

In this paper, we report a comparison of the two methods for testing antifungal activity of A. leucotrichus essential oil in order to determine which method produces the most reliable results. The PF and VA methods appeared to give an indication of the susceptibility of specific fungi. According to the results obtained, VA method in disc volatilization has better antifungal activity against the pathogens tested than that in liquid phase observed in the PF assay. Similarity behavior was observed with perillaldehyde which its vapor-phase efficacies on mycelial growth were greater than the contact-phase efficacies (Tian et al., 2015a).This result indicates that the substances in direct contact method were less efficient than that in the disc volatilization method. The efficacy of essential oils in vapour state was probably attributable to the direct deposition of essential oils on lipophilic fungal mycelia together with an indirect effect via adsorption through the agar medium (Zani et al., 1991). These results are in agreement with those reported in the literature (Zani et al., 1991 ; Sikkema, 1993).

The essential oils are complex mixtures of many different aromatic components with various degrees of lipophilicity and relative hydrophilicity given by the presence of constituents with polar functional groups (Sikkema et al., 1992). When added to a medium, the essential oils distributes more or less into the aqueous phase depending on its relative hydrophilicity.

Hence, an essential oil with constituents with low water solubility should dissolve little in aqueous medium, and consequently should show a weak activity. These essential oils, however, showed very good activity when assayed by VA and this might related to their high volatility (Zani et al., 1991). These observations suggest that the physical and chemical properties (solubility and volatility) can have considerable effect on the in vitro antimicrobial activity (Tullio et al., 2007).

\section{CONCLUSION}

Essential oil is one of the most promising groups of natural compounds for the development of safer antifungal agents. In continuation with our interest in antifungal substances from plant sources, we performed preliminary studies with $A$. leucotrichus which revealed significant antifungal activity against three phytopathogenic fungi causing severe diseases in apple such as $B$. cinerea, $P$. expansum and $R$. stolonifer. The results demonstrate that this essential oil is effective for inhibition or control of phytopathogens and so could be used as potential alternative to synthetic fungicides for the protection of apples from phytopathogenic fungi. The use of A. leucotrichus oil in vapour phase could have additional advantages such as efficacy without requiring direct contact resulting in ease of application and no alteration in organoleptic properties of the edible material/food. With respect to above-mentioned data, our findings demonstrate that A. leucotrichus oil vapour may be considered as a potential agent for preventing microbial mediated food spoilage. A further study in vivo condition is warranted to confirm the antifungal activity of A. leucotrichus, which may be used for preservation and/or extension the shelf life of raw and processed food.

\section{REFERENCES}

Abu Zarga M.H., Al-Jaber H.I., Baba Amer Z.Y., Sakhrib L, Al-humaidi J.Y.G., M.A., Abaza I.F., Afif F.U. Chemical Composition, Antimicrobial and Antitumor Activities of Essential Oil of Ammodaucus leucotrichus Growing in Algeria. TBAP. 2013; 3 (3), 224231.

Barnett H.L., Hunter B.B. (1972). Illustrated genera of imperfect fungi.Minneapolis: Burgess Publishing Company.

Beghali M., Ghalem S., Allali H., Belouatek A., Marouf Malay A. Effects of an aqueous extract from Ammodaucus leucotrichus on Calcium Oxalate Crystallization in vitro. J. Biochem. Molec. Biol. 2008; 16-11.

Bellakhdar J. La pharmacopée marocaine traditionnelle. Médecine arabe ancienne et savoirs populaires. IBIS Press, (1979): 764.

Eckert J.W., Ogawa J.M. The chemical control of postharvest diseases: Deciduous fruits, berries, vegetables and root/tuber crops. Ann. Rev. Phytopathol. 1988; 26, 433-69.

El-Haci I.A., Bekhechi C., Atik-Bekkara F., Mazari W., Gherib M., Bighelli A., Casanova J., F. Antimicrobial activity of Ammodaucus leucotrichus fruit oil from Algerian Sahara. Nat Prod Commun. 2014; 9(5), 711-2.

Gumus T., Demirci AS., Sagdic O., Arici M. Inhibition of heat resistant molds: Aspergillus fumigates and Paecilomyces variotii by some plant essential oils. Food Sci. Biotechnol. 2010; 19, 1241-1244.

\section{Cambridge. (1998)}

Maberly P.L. The Plant Book, Cambridge University Press,

Manssouri M., El Ouadi Y., Znini M., Costa J., Bouyanzer A., Desjobert J.M., Majidi L. Adsorption proprieties and inhibition of mild steel corrosion in $\mathrm{HCl}$ solution by the essential oil from fruit of Moroccan Ammodaucus leucotrichus. J. Mater. Environ. Sci. 2015; 6, 631-646.

Ozenda P. (1991). Flore et végétation du Sahara. $3 \mathrm{rd}^{\text {ed }}$. CNRS,

Paris.

Panahirad S., Zaare-Nahandi F., Safaralizadeh R., AlizadehSalteh S. Postharvest control of Rhizopus stolonifer in peach (Рrunu spersica L. Batsch) fruits using salicylic acid. J. Food Saf. 2012; 32, 502507.

Pandey D.K., Tripathi N.N., Tripathi R.D., Dixit SN., Fungitoxic and phytotoxic properties of the essential oil of $H$. suaveolens. Z. Panzenk. Panzen. 1982; 89, 344-349. 
Rhayour K., Bouchikhi T., Tantaoui-ElarakiA., Sendide K., Remmal, A. The mechanism of bactericidal action of Oregano and clove essential oils and their phenolic major components on Escherichia coli and Bacillus subtilis. J. Essent. Oil Res. 2012; 15, 286-292.

Sato k., Krist S., Buchbauer G. Antimicrobial Effect of transCinnamaldehyde, Perillaldehyde, Citronellal, Citral, Eugenol and Carvacrol on Airborne Microbes Using an Air washer. Biol. Pharm. Bull. 2006; 29(11), 2292-2294.

Sikkema J. (1993). Microbial transformation of tetralin. Ph.D. Thesis, Agricultural University, Wageningen, Netherlands.

Sikkema J., Poolman B., Konings W.N., De Bont J.A.M. Effects of the membrane action of tetralin on the functional and structural properties of artificial and bacterial membranes. J. Bacteriol. 1992; 174, 2986-2992.

Soylu EM., Kurt S., Soylu S. In vitro and in vivo antifungal activities of the essential oils of various plants against tomato grey mould disease agent Botrytis cinerea. Int. J. Food Microbiol. 2010; 143: 183-189.

Suhr K.I., Nielsen P.V.J. Antifungal activity of essential oils evaluated by two different application techniques against rye bread spoilage fungi. Appl. Microbiol. 2003; 94, 665-674.

Tian J., Zeng X., Lü A., Zhu A., Peng X., Wang Y. Perillaldehyde, a potential preservative agent in foods: Assessment of antifungal activity against microbial spoilage of cherry tomatoes.LWTFood Sci. Technol. 2015a; 60, 63-70.

Tian J., Wang Y., Zeng H., Li Z., Zhang P., Tessema A., Peng $X$. Efficacy and possible mechanisms of perillaldehyde in control of Aspergillus niger causing grape decay. Int. J. Food Microbiol. 2015b; 202, $27-34$.

Tolouee M., Alinezhad S., Saberi R., Eslamifar A., Zad S. J. Jaimand K. Effect of Matricaria chamomilla L. flower essential oil on the growth and ultra structure of Aspergillus niger var Tieghem. Food Sci. Technol. Int. 2010; 139(3), 127-133.
Tullio V., NostroA., Mandras N., Dugo P., Banche G., Cannatelli M.A., Cuffini A.M., Alonzo V., Carlone N.A. Antifungal activity of essential oils against filamentous fungi determined by broth microdilution and vapour contact methods. J. Appl. Microbiol. 2007; 102, $1544-1550$.

Ultee A., Bennik M. H. J., Moezelaar R. The phenolic hydroxyl group of carvacrol is essential for action against the food-borne pathogen Bacillus cereus. Appl. Environ. Microbiol. 2002; 68, 1561-1568.

Zambonelli A., Zechini d'Aulerio, A., Bianchi A., Albasini A. Effects of essential oil on phytopathogenic fungi. Phytopathology. 1996; 144, 491-494.

Zani F., Massimo G., Benvenuti S., Bianchi A., Albasini A., Melegari M., Vampa G., Bellotti A., Mazza P. Studies on the genotoxic properties of essential oils with Bacillus subtilis rec-assay and Salmonella/microsome reversion assay. Planta Medicina. 1991; 57, 327 241.

Znini M, Cristofari G, Majidi L, Mazouz H, Tomi P, Paolini J, Costa J. Antifungal activity of essential oil from Asteriscus graveolens against postharvest phytopathogenic fungi in apples. Nat. Prod. Commun. $2011 ; 6,1763-1768$.

\section{How to cite this article:}

Manssouri M, Znini M, El-Harrak A, Majidi L. Antifungal activity of essential oil from the fruits of Ammodaucus leucotrichus Coss. $\&$ Dur., in liquid and vapour phase against postharvest phytopathogenic fungi in apples. J App Pharm Sci, 2016; 6 (05): 131-136. 